\title{
Slow-Pull Using a Fanning Technique Is More Useful Than the Standard Suction Technique in EUS-Guided Fine Needle Aspiration in Pancreatic Masses
}

Jae Min Lee, Hong Sik Lee, Jong Jin Hyun, Jung Min Lee, In Kyung Yoo, Seung Han Kim, Hyuk Soon Choi, Eun Sun Kim, Bora Keum, Yeon Seok Seo, Yoon Tae Jeen, Hoon Jai Chun, Soon Ho Um, and Chang Duck Kim

Division of Gastroenterology and Hepatology, Department of Internal Medicine, Korea University College of Medicine, Seoul, Korea

Background/Aims: Endoscopic ultrasound-guided fine needle aspiration (EUS-FNA) is useful for obtaining pancreatic mass samples. The combination of modified techniques (i.e., slow-pull technique and fanning technique) may improve the quality of the sample obtained by EUS-FNA. We investigated the effectiveness of a combined slow-pull fanning technique in EUS-FNA for pancreatic mass. Methods: This prospective comparative study investigated EUS-FNA performed for pancreatic solid masses between August 2015 and July 2016. Pairwise specimens were alternately obtained using the following two techniques for targeted pancreatic lesions: standard suction or slow-pull with fanning. We compared the specimen quality, blood contamination, and diagnostic accuracy of these techniques. Results: Forty-eight consecutive patients were included (29 men; mean age, 68.1 \pm 11.9 years), and 96 pancreatic mass specimens were obtained. The slow-pull with fanning technique had a significantly superior diagnostic accuracy than the suction technique (88\% vs $71 \%, p=0.044)$. Furthermore, blood contamination was significantly reduced using the slow-pull with fanning technique (ratio of no or slight contamination, $77 \%$ vs $56 \%, p=0.041$ ). No difference was observed in the acquisition of adequate cellularity between the groups. In the subgroup analysis, the tumor size and sampling technique were related to the EUSFNA diagnostic accuracy. Conclusions: The slow-pull with needle fanning technique showed a good diagnostic yield for EUS-FNA for pancreatic mass. This technique can be useful for performing EUS-guided sampling for diagnosing pancreatic disease. (Gut Liver 2018;12:360-366)

Key Words: Pancreas; Endosonography; Biopsy, fine-needle;
Technique

\section{INTRODUCTION}

Endoscopic ultrasonography (EUS) is a useful tool for the diagnosis of digestive tract diseases. Since pathologic confirmation is essential for making treatment decisions, EUS-guided fine needle aspiration (EUS-FNA) has been widely used for the diagnosis of pancreatic lesions. The diagnostic values for pancreatic mass were as follows: sensitivity of 54\% to $96 \%$, specificity of $96 \%$ to $98 \%$, and accuracy of $83 \%$ to $95 \% .^{1-4}$ Despite developments in aspiration needle devices and echoendoscopes, the diagnostic accuracy of EUS-FNA is not satisfactory in the actual practice. Moreover, because of its high cost, repeated examinations would become a heavy burden for patients with pancreatic lesions. To improve the diagnostic yield, investigators have studied EUS-FNA using various needle sizes, shapes, and aspiration techniques. ${ }^{1,3,5-7}$ Among these techniques, the fanning technique, which involves sampling multiple areas within a lesion during each pass, was found to be superior to the standard approach because fewer passes are required to establish the diagnosis. ${ }^{8}$ Further, the new technique named as "slow-pull technique" was recently introduced in EUS-FNA. ${ }^{9}$ The slow-pull technique was performed as follows: targeting mass via EUS, puncturing, and slowly pulling out the stylet without suction. According to their results, less contamination with blood and higher diagnostic yield were found. Similar results were observed in another study in which a 22-gauge core needle was used. $^{10}$

However, although many options are available for EUS-FNA, the optimal method for EUS-FNA for pancreatic lesions has not

\footnotetext{
Correspondence to: Hong Sik Lee

Division of Gastroenterology and Hepatology, Department of Internal Medicine, Korea University Medical Center, Korea University College of Medicine, 73 Inchon-ro, Seongbuk-gu, Seoul 02841, Korea

Tel: +82-2-920-6555, Fax: +82-2-953-1943, E-mail: hslee60@korea.ac.kr

Received on March 23, 2017. Revised on September 9, 2017. Accepted on September 20, 2017. Published online February 8, 2018 pISSN 1976-2283 eISSN 2005-1212 https://doi.org/10.5009/gnl17140

() This is an Open Access article distributed under the terms of the Creative Commons Attribution Non-Commercial License (http://creativecommons.org/licenses/by-nc/4.0) which permits unrestricted non-commercial use, distribution, and reproduction in any medium, provided the original work is properly cited.
} 
been established yet. We hypothesized that the combination of new techniques may be effective for an adequate tissue acquisition by EUS-FNA from the pancreas. Since the diagnostic accuracy would be closely related to the degree of blood contamination, the slow-pull technique can be a useful method for EUS-FNA. Moreover, the fanning technique is helpful in tissue acquisition from the pancreatic tumor to avoid passing through the necrotic tumor portion. Therefore, we developed a "slow-pull with fanning" technique to obtain adequate pancreatic samples via EUS-FNA.

In this study, we prospectively evaluated the diagnostic yield and effectiveness of the slow-pull with fanning technique and compared them with those of the standard suction technique in patients with pancreatic masses.

\section{MATERIALS AND METHODS}

\section{Patients}

This study was a prospective comparative study and conducted between August 2015 and July 2016 at a tertiary medical center in Seoul, Korea. The inclusion criteria were as follows: (1) age over 19 years; (2) presence of a pancreatic mass lesion shown on abdominal computed tomography and/or magnetic resonance imaging; (3) need for cytological evaluation of pancreatic lesions via EUS-FNA; (4) no previous intervention for the pancreas; and (5) written informed consent. The exclusion criteria were as follows: (1) history of anti-platelet agent and warfarin use or bleeding tendency; (2) severe comorbidity; (3) cystic lesion without a solid component; and (4) failure to visualize the pancreatic mass via EUS. This study was approved by the Institutional Review Board of Korea University Anam Hospital (IRB number: ED16337) and performed in accordance with the principles of the Declaration of Helsinki. Written informed consents were obtained.

\section{Methods and procedures}

Two endosonographers performed the EUS-FNA procedures using a similar process. The patients under conscious sedation were placed in the left lateral position. The pairwise pancreatic specimens were alternately obtained using different techniques: one obtained by slowly pulling the stylet with a fanning motion (Fig. 1A) and the other by standard suction with negative pressure (Fig. 1B). The first and second passes were performed at similar angles, approaches, and distances for the pancreatic mass. The order of the technique used was randomly selected, and a pair of specimen was obtained from the same pancreatic lesion. If the number of specimens were $>3$, their results were excluded in the analysis, and only the first/second specimens were analyzed. The detailed process of the EUS-FNA techniques was as follows. After the visualization of a pancreatic mass using linear EUS, the scope approached the nearest puncture route without intervening the vessels. The distance, location, and size of the pancreatic mass were measured for needle puncture (Fig. $2 \mathrm{~A})$. The tip of the needle was positioned at the right side of the image, and puncture was performed (Fig. 2B).

In the slow-pull technique, the stylet was slowly retracted with fanning of the needle in the pancreatic mass (Fig. 2C). Ten to twenty to-and-fro movements were made with minimal negative pressure provided by slow pull of stylet. ${ }^{9}$ The length of stylet retraction was about $1 \mathrm{~m}$ and the time of stylet retraction was from 40 to 60 second. For fanning method, the needle was placed in four different areas in the mass and then moved 3 to 5 times back and forth in each area. ${ }^{8}$ In the standard suction technique, the stylet was rapidly extracted after puncturing, and the syringe enclosed in the EUS-FNA kit was used for negative pressure (Fig. 2D). The number of to-and-fro movements was 10 to 20 times in both techniques. EUS-FNA specimens were evaluated by one experienced pathologist who was blinded to this study. Liquid-based preparation cytology was used to im-
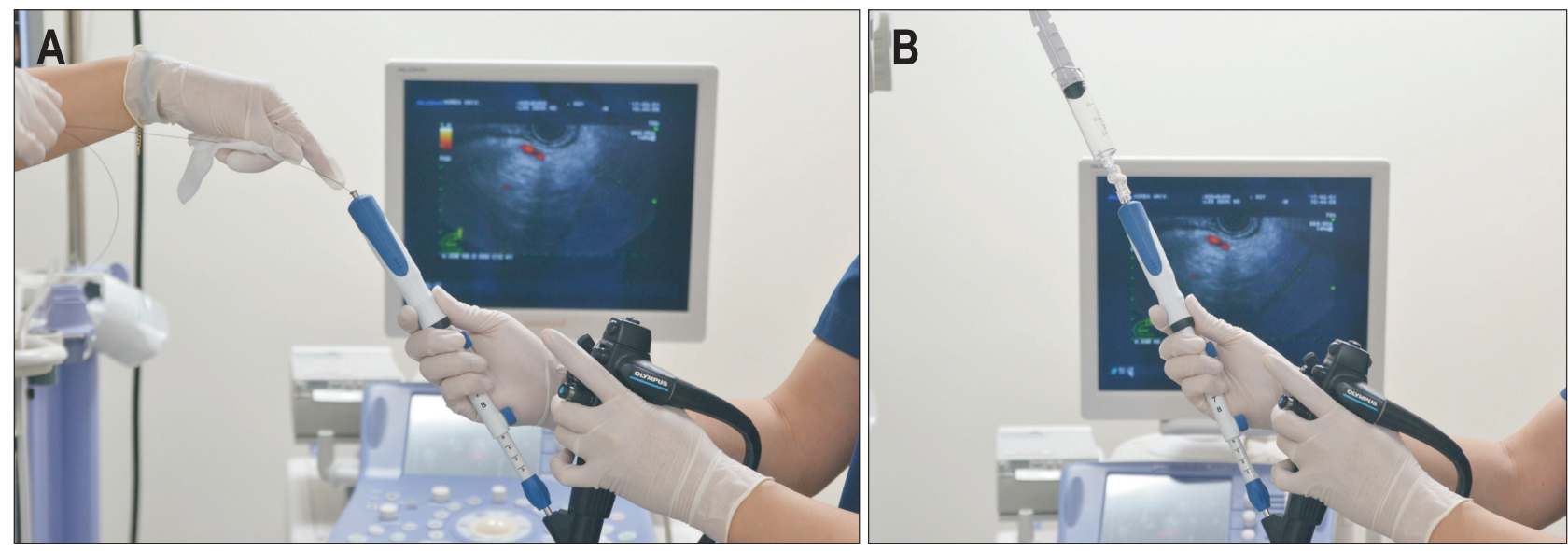

Fig. 1. Endoscopic ultrasound-guided fine needle aspiration procedure techniques to obtain samples of pancreatic masses; slow-pull technique (A) and standard suction technique (B). 

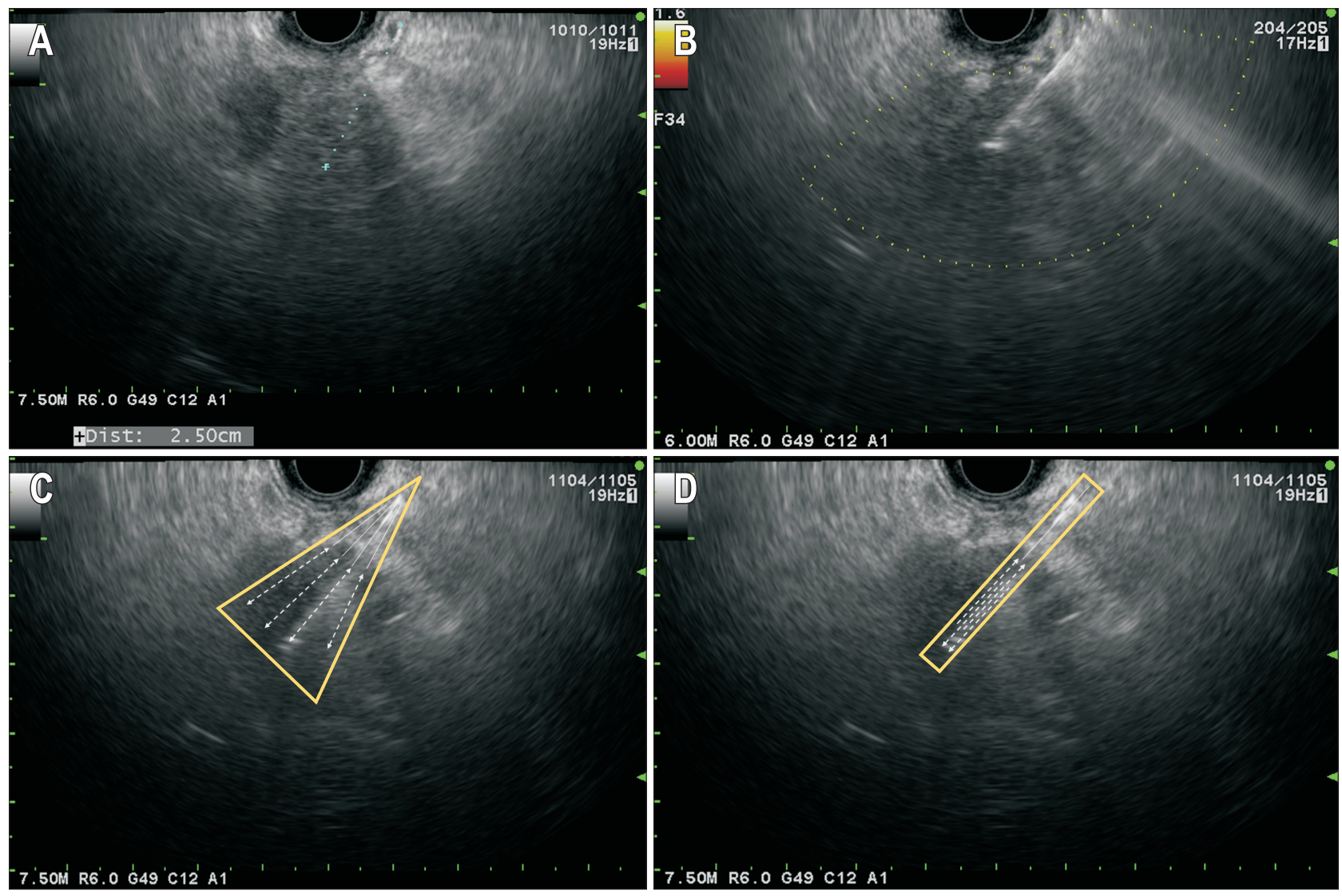

Fig. 2. Endosonographic view of the pancreatic masses during the endoscopic ultrasound-guided fine needle aspiration procedure targeting (A), needle passing (B), to-and-fro movements with fanning (C), and to-and-fro movements only (D).

prove the quality of cytological preparations, but not rapid onsite evaluation.

\section{Equipment for EUS-FNA}

All EUS-FNA procedures were performed using the linear EUS (GF-UCT240; Olympus Medical Systems, Tokyo, Japan) and 22-gauge FNA needle (Expect Slimline Endoscopic Ultrasound Aspiration Needle; Boston Scientific, Natick, MA, USA). EUS images were obtained using the Aloka ProSound Alpha 10 Premier (Aloka, Tokyo, Japan).

\section{Outcomes of EUS-FNA and definitions}

The results of the EUS-FNA using the standard suction technique and slow-pull with fanning technique were compared. The primary outcome was the diagnostic accuracy of EUS-FNA for the final diagnosis. The secondary outcomes were the rate of obtaining an adequate cellularity and grade of blood contamination. The clinical factors were also analyzed to identify the correlation with diagnostic accuracy: tumor size $(<2.5 \mathrm{~cm}$ vs $\geq 2.5 \mathrm{~cm}$ ), tumor location (uncinate process/head vs body/ tail), and FNA technique (suction vs slow pull). The assessment was graded with predefined criteria by a pathologist who was blinded to the technique of histological assessment (Table 1). ${ }^{9}$ The quantity was classified as "adequate" and "inadequate."
Table 1. Grading Scale for the Histological Assessments of the Fine Needle Aspiration Sample

\begin{tabular}{|c|c|}
\hline \multicolumn{2}{|l|}{ Quantity } \\
\hline Adequate & $\begin{array}{l}\text { Sufficient amount of representative cells for } \\
\text { pathological diagnosis }\end{array}$ \\
\hline Inadequate & $\begin{array}{l}\text { Scanty or insufficient amount of representative } \\
\text { cells for pathological diagnosis }\end{array}$ \\
\hline \multicolumn{2}{|c|}{ Blood contamination } \\
\hline Low & $\begin{array}{l}\text { No or few blood cells with influence on the } \\
\text { diagnosis }\end{array}$ \\
\hline Moderate & $\begin{array}{l}\text { Partial interference by blood cells but } \\
\text { pathological diagnosis possible }\end{array}$ \\
\hline High & $\begin{array}{l}\text { Interference with the making of pathological } \\
\text { diagnosis due to large amount of blood cells }\end{array}$ \\
\hline
\end{tabular}

And the grade of blood contamination was classified as "low," "moderate," and "high." The cytological diagnosis of pancreatic lesion was based on the suggestive result and final report from pathologist. The final diagnosis was determined by the histological diagnosis after surgically resection or positive result for malignancy in cytopathology with compatible clinical outcomes. When the result of the EUS-FNA was negative for malignancy, the patients were followed up for $>6$ months. The lesion was 
considered as benign if the clinical course revealed no deterioration during follow-up over 6 months. ${ }^{7,9}$

\section{Statistical analysis}

We estimated the diagnostic accuracy as 50\% to $80 \%$ per each pass in EUS-FNA. ${ }^{11-13}$ Sample size was calculated with the $G^{*}$ power program 3.1.9.2 for the goodness-of-fit tests with effect size of $0.5, \alpha$-value of 0.05 and power of $80 \%$. Assuming a drop-out rate of $20 \%$, a total of around 55 patients were needed to be enrolled. All continuous variables were presented as mean \pm standard deviations and categorical variables as numbers and proportions. Statistical analysis was conducted using the Pearson chi-square test or Fisher exact test for comparison of accuracy and the Mann-Whitney U-test for continuous variables. Additionally, univariate and multivariate logistic regression analyses for diagnostic accuracy were performed using tumor size, tumor location, and FNA technique as possible related factors. p-values $<0.05$ were considered statistically significant. Data were analyzed using the Statistical Package for the Social Sciences version 20.0 (IBM Corp., Armonk, NY, USA).

\section{RESULTS}

\section{Patient characteristics}

Between August 2015 and July 2016, 55 patients underwent EUS-FNA for pancreatic lesion were enrolled in this study. A total of 48 patients were included and seven patients were excluded: three patients underwent EUS-FNA using only one technique, three patients whose procedures had used a ProCore needle or 25-gauge needle, and one patient who was lost to follow-up. The baseline characteristics and final diagnoses of the patients are shown in Table 2. The mean age was $68.1 \pm 11.9$ years, and 29 patients (60\%) were men. The final diagnoses were malignant in 40 cases (83\%) and benign in eight cases (17\%).

Table 2. Characteristics of the Patients with Pancreatic Masses

\begin{tabular}{lc}
\hline \multicolumn{1}{c}{ Variable } & Value \\
\hline No. of patients & 48 \\
Male sex & $29(60)$ \\
Age, yr & $68.1 \pm 11.9$ \\
Tumor size, mm & $37.6 \pm 16.7$ \\
Tumor location & \\
Uncinate process & $12(25)$ \\
Head & $14(29)$ \\
Body & $15(31)$ \\
Tail & $7(15)$ \\
Final diagnosis & \\
Malignant tumor & $40(83)$ \\
Benign lesion & $8(17)$
\end{tabular}

Data are presented as number $(\%)$ or mean \pm SD.

\section{Procedure result and diagnostic accuracy in each technique}

In all patients with pancreatic masses, the slow-pull with fanning and standard suction techniques were alternately performed in obtaining a pancreatic specimen. A total of 96 specimens (48 pairs) were obtained from the pancreatic lesions, and the results are shown in Tables 3 and 4. The slow-pull with fanning technique showed a better diagnostic accuracy than the standard suction technique ( $88 \%$ vs $71 \%, \mathrm{p}=0.044$ ). Blood contamination was significantly less using the slow-pull with fanning technique than that using the standard suction technique (rate of none/low blood contamination; 56\% in the standard suction technique vs $77 \%$ in the slow-pull with fanning technique, $\mathrm{p}=0.041$ ). In the slow-pull with fanning technique, $4 \%$ of the specimens had an inadequate quantity, but were not significant. None of the patients encountered clinically significant complication such as gastrointestinal bleeding, perforation or death as a result of the procedure.

Table 3. Comparison of the FNA Results Using the Two Techniques

\begin{tabular}{llccc}
\hline & Total & $\begin{array}{c}\text { Standard } \\
\text { suction } \\
\text { technique }\end{array}$ & $\begin{array}{c}\text { Slow-pull } \\
\text { with fanning } \\
\text { technique }\end{array}$ & p-value \\
\hline $\begin{array}{l}\text { No. of samples } \\
\text { Diagnostic accuracy }\end{array}$ & 96 & 48 & 48 & 0.044 \\
$\begin{array}{l}\text { Correct diagnosis } \\
\text { Incorrect diagnosis }\end{array}$ & $20(21)$ & $14(29)$ & $6(12)$ & \\
FNA results & $60(63)$ & $26(54)$ & $34(71)$ & 0.118 \\
True positive & $34(71)$ & $42(88)$ & \\
True negative & $16(17)$ & $8(17)$ & $8(17)$ & \\
False negative & $20(21)$ & $14(29)$ & $6(12)$ & \\
\hline
\end{tabular}

Data are presented as number (\%).

FNA, fine needle aspiration.

Table 4. Comparison of the Quality of the Fine Needle Aspiration Samples Using the Two Techniques

\begin{tabular}{|c|c|c|c|c|}
\hline & Total & $\begin{array}{l}\text { Standard } \\
\text { suction } \\
\text { technique }\end{array}$ & $\begin{array}{l}\text { Slow-pull } \\
\text { with fanning } \\
\text { technique }\end{array}$ & p-value \\
\hline No. of samples & 96 & 48 & 48 & \\
\hline \multicolumn{4}{|l|}{ Histological assessments } & 0.495 \\
\hline Adequate quantity & $94(98)$ & $48(100)$ & 46 (96) & \\
\hline Inadequate quantity & $2(2)$ & 0 & $2(4)$ & \\
\hline Blood contamination & & & & 0.041 \\
\hline Low & $64(67)$ & $27(56)$ & 37 (77) & \\
\hline Moderate & $17(18)$ & $13(27)$ & $4(8)$ & \\
\hline High & 15 (15) & 8 (17) & 7 (15) & \\
\hline
\end{tabular}

Data are presented as number (\%). 
Table 5. Univariate and Multivariate Analyses of the Clinical Parameters of the Accuracy of EUS-FNA

\begin{tabular}{|c|c|c|c|c|c|}
\hline \multirow{2}{*}{ Parameter } & \multirow{2}{*}{ No. } & \multicolumn{2}{|c|}{ Univariate analysis } & \multicolumn{2}{|c|}{ Multivariate analysis } \\
\hline & & OR $(95 \% \mathrm{CI})$ & p-value & OR $(95 \% \mathrm{CI})$ & p-value \\
\hline \multicolumn{6}{|l|}{ Location of mass } \\
\hline Body/tail & 44 & 1 & & & \\
\hline Uncinate/head & 52 & $1.76(0.63-4.9)$ & 0.278 & & \\
\hline \multicolumn{6}{|l|}{ Mass size, $\mathrm{cm}$} \\
\hline$<2.5$ & 20 & 1 & & 1 & \\
\hline$\geq 2.5$ & 76 & $3.56(1.20-10.53)$ & 0.022 & $3.83(1.24-11.87)$ & 0.020 \\
\hline \multicolumn{6}{|l|}{ Sampling technique } \\
\hline Slow-pull with fanning technique & 48 & 1 & & 1 & \\
\hline Standard suction technique & 48 & $2.88(1.01-8.30)$ & 0.050 & $3.10(1.03-9.29)$ & 0.044 \\
\hline
\end{tabular}

EUS-FNA, endoscopic ultrasonography-guided fine needle aspiration; OR, odds ratio; CI, confidence interval.

\section{Clinical factors related to the accuracy of EUS-FNA for pancreatic masses}

The univariate analysis was performed to define the clinical factors associated with the diagnostic accuracy of EUS-FNA for pancreatic lesions (Table 5). There was no significant difference in mass location in this study. However, tumor size and EUS-FNA technique were significantly related to the diagnostic accuracy for the pancreatic masses. Sampling technique was a significant factor related to the diagnostic accuracy of EUS-FNA in the univariate analysis ( $\mathrm{p}=0.050$; odds ratio, 2.88; 95\% confidence interval, 1.01 to 8.30 ). In the multivariate analysis, mass size and FNA technique were related to the diagnostic yield of FNA. The slow-pull with fanning technique was superior to the standard suction technique in the EUS-FNA for the pancreas.

\section{DISCUSSION}

Since its introduction in the early 1990s, EUS-FNA has emerged as a safe and accurate technique for the diagnosis of gastrointestinal diseases. ${ }^{14,15}$ Although EUS-FNA is a key procedure for the pathologic confirmation of pancreatic tumors, a wide variation in the FNA technique for the acquisition of specimens from the pancreas still exists. Indeed, the various factors that influence the accuracy of EUS-FNA include tumor size, tumor location, and sonographic characteristics. Moreover, factors such as needle size, ${ }^{16-19}$ needle type, ${ }^{20-22}$ scope position, ${ }^{23}$ with or without suction, ${ }^{24,25}$ with or without stylet, ${ }^{26,27}$ and onsite evaluation ${ }^{28}$ are also related. Prior studies focused on the technical aspects of EUS-FNA, such as choice of needle, sampling methods, number of fine needle passes, and methods for collecting specimens. However, there is no definite solution to the unmet needs in pancreatic tissue acquisition. How we can obtain enough specimens with good cellularity and minimize blood contamination are key points on this topic.

In the present study, we focused not only on the capillary pressure during EUS-FNA on the pancreas but also on the sampling technique after the passes. Although the continuous suction with syringes provided good cellularity and specimen quantity, blood contamination or tissue injury can occur during sampling. In the literature review, the slow-pull technique showed a better quality of specimen, ${ }^{29}$ and lesser blood contamination in the pancreatic lesion. ${ }^{7}$ According to recently published articles, the fanning technique had a significantly higher first pass diagnostic accuracy compared with the standard FNA technique. ${ }^{8}$ However, although a high pressure with fanning technique could be helpful in obtaining a specimen, it could also increase the rate of blood contamination or injury without improving the diagnostic yield. ${ }^{20,26}$ We considered that the combination of the two techniques, "slow-pull" and "fanning" techniques, would make a synergistic effect in improving the quality of specimens and in decreasing blood contamination during EUS-FNA for pancreatic masses.

Based on the present results, the diagnostic accuracy of the slow-pull with fanning technique was $89 \%$, which is higher than $69 \%$ of the standard suction technique. Both techniques showed an equal quantity of EUS-FNA specimens; however, blood contamination was significantly greater when the standard suction technique was used. Consequently, although the slow-pull with fanning technique had a weak suction force, the sample was satisfactorily obtained with an adequate quantity. Moreover, it was useful in the acquisition of pancreatic specimens with lesser blood contaminations.

The present study differs from those already in the literature in that it was a prospective comparative study that alternately used two different techniques in the same pancreatic mass. Further, we performed the slow-pull technique combined with the fanning technique for EUS-FNA and found the technique with the fanning movement of the needle to be a safe and effective method that can provide an accurate information on pancreatic diseases. Tissue injury and blood contamination from excessive movements during the fanning technique should be of concern. 
However, the negative pressure in the slow-pull with fanning technique was lower than that in the standard suction technique. Therefore, the slow-pull with fanning technique could reduce blood contamination and improve the diagnostic yield of EUS-FNA.

There were some limitations in the present study. First, the total number of patients enrolled was small. Although the sample size was calculated based on the diagnostic accuracy, larger sample sizes would be required to clarify the factors associated with the diagnostic yield. Second, a rapid on-site evaluation was not available in our center owing to limited time, resources, and financial consideration. If possible, the sampling should be conducted in the presence of an on-site cytopathological evaluation. Third, we performed EUS-FNA targeting only a single spot of the mass lesions; however, it could be related to a high false negative rate. Since necrotic areas of the lesions will decrease the diagnostic adequacy, sampling both central and peripheral areas of the lesions via FNA could enhance it. Fourth, only 22-gauge needles were used for the EUS-FNA in this study. Using 25-gauge needles, particularly for sampling the pancreatic head and uncinate process, would be convenient and safe. Finally, whether the superior diagnostic accuracy came from slow-pull method or fanning technique was not considered. Since fanning technique can be also applied to standard suction method, it should be considered to include the fanning technique with standard negative suction.

In summary, the present study demonstrates that EUS-FNA using the slow-pull with fanning technique is useful in obtaining adequate pancreatic mass specimens. We found that this technique can decrease blood contamination and provide an accurate information for the precise diagnosis of patients with pancreatic masses.

\section{CONFLICTS OF INTEREST}

No potential conflict of interest relevant to this article was reported.

\section{ACKNOWLEDGEMENTS}

This research was supported by the Ministry of Trade, Industry \& Energy (MOTIE, Korea) under Industrial Technology Innovation Program (grant number: 10060251) and the Korea Health Technology R\&D Project through the Korea Health Industry Development Institute (KHIDI), funded by the Ministry of Health \& Welfare, Republic of Korea (grant number: HI14C3477) and a Korea University Grant.

\section{REFERENCES}

1. Hewitt MJ, McPhail MJ, Possamai L, Dhar A, Vlavianos P, Monahan KJ. EUS-guided FNA for diagnosis of solid pancreatic neo- plasms: a meta-analysis. Gastrointest Endosc 2012;75:319-331.

2. Itoi T, Sofuni A, Itokawa F, Irisawa A, Khor CJ, Rerknimitr R. Current status of diagnostic endoscopic ultrasonography in the evaluation of pancreatic mass lesions. Dig Endosc 2011;23 Suppl 1:1721.

3. Puli SR, Bechtold ML, Buxbaum JL, Eloubeidi MA. How good is endoscopic ultrasound-guided fine-needle aspiration in diagnosing the correct etiology for a solid pancreatic mass? A metaanalysis and systematic review. Pancreas 2013;42:20-26.

4. Hwang CY, Lee SS, Song TJ, et al. Endoscopic ultrasound guided fine needle aspiration biopsy in diagnosis of pancreatic and peripancreatic lesions: a single center experience in Korea. Gut Liver 2009;3:116-121.

5. Affolter KE, Schmidt RL, Matynia AP, Adler DG, Factor RE. Needle size has only a limited effect on outcomes in EUS-guided fine needle aspiration: a systematic review and meta-analysis. Dig Dis Sci 2013;58:1026-1034.

6. Chen J, Yang R, Lu Y, Xia Y, Zhou H. Diagnostic accuracy of endoscopic ultrasound-guided fine-needle aspiration for solid pancreatic lesion: a systematic review. J Cancer Res Clin Oncol 2012;138:1433-1441.

7. Chen JY, Ding QY, Lv Y, et al. Slow-pull and different conventional suction techniques in endoscopic ultrasound-guided fineneedle aspiration of pancreatic solid lesions using 22-gauge needles. World J Gastroenterol 2016;22:8790-8797.

8. Bang JY, Magee SH, Ramesh J, Trevino JM, Varadarajulu S. Randomized trial comparing fanning with standard technique for endoscopic ultrasound-guided fine-needle aspiration of solid pancreatic mass lesions. Endoscopy 2013;45:445-450.

9. Nakai $\mathrm{Y}$, Isayama $\mathrm{H}$, Chang $\mathrm{KJ}$, et al. Slow pull versus suction in endoscopic ultrasound-guided fine-needle aspiration of pancreatic solid masses. Dig Dis Sci 2014;59:1578-1585.

10. Paik WH, Park Y, Park DH, et al. Prospective evaluation of new 22 gauge endoscopic ultrasound core needle using capillary sampling with stylet slow-pull technique for intra-abdominal solid masses. J Clin Gastroenterol 2015;49:199-205.

11. Turner BG, Cizginer S, Agarwal D, Yang J, Pitman MB, Brugge WR. Diagnosis of pancreatic neoplasia with EUS and FNA: a report of accuracy. Gastrointest Endosc 2010;71:91-98.

12. Ryozawa S, Kitoh H, Gondo T, et al. Usefulness of endoscopic ultrasound-guided fine-needle aspiration biopsy for the diagnosis of pancreatic cancer. J Gastroenterol 2005;40:907-911.

13. Weston BR, Bhutani MS. Optimizing diagnostic yield for EUSguided sampling of solid pancreatic lesions: a technical review. Gastroenterol Hepatol (N Y) 2013;9:352-363.

14. Vilmann P, Jacobsen GK, Henriksen FW, Hancke S. Endoscopic ultrasonography with guided fine needle aspiration biopsy in pancreatic disease. Gastrointest Endosc 1992;38:172-173.

15. Dumonceau JM, Polkowski M, Larghi A, et al. Indications, results, and clinical impact of endoscopic ultrasound (EUS)-guided sampling in gastroenterology: European Society of Gastrointestinal Endoscopy (ESGE) clinical guideline. Endoscopy 2011;43:897-912. 
16. Itoi T, Itokawa F, Kurihara T, et al. Experimental endoscopy: objective evaluation of EUS needles. Gastrointest Endosc 2009;69(3 Pt 1):509-516.

17. Yusuf TE, Ho S, Pavey DA, Michael H, Gress FG. Retrospective analysis of the utility of endoscopic ultrasound-guided fine-needle aspiration (EUS-FNA) in pancreatic masses, using a 22-gauge or 25-gauge needle system: a multicenter experience. Endoscopy 2009;41:445-448.

18. Song TJ, Kim JH, Lee SS, et al. The prospective randomized, controlled trial of endoscopic ultrasound-guided fine-needle aspiration using $22 \mathrm{G}$ and $19 \mathrm{G}$ aspiration needles for solid pancreatic or peripancreatic masses. Am J Gastroenterol 2010;105:1739-1745.

19. Madhoun MF, Wani SB, Rastogi A, et al. The diagnostic accuracy of 22-gauge and 25-gauge needles in endoscopic ultrasoundguided fine needle aspiration of solid pancreatic lesions: a metaanalysis. Endoscopy 2013;45:86-92.

20. Iwashita T, Nakai Y, Samarasena JB, et al. High single-pass diagnostic yield of a new 25-gauge core biopsy needle for EUSguided FNA biopsy in solid pancreatic lesions. Gastrointest Endosc 2013;77:909-915.

21. Inoue T, Okumura F, Mizushima T, et al. Assessment of factors affecting the usefulness and diagnostic yield of core biopsy needles with a side hole in endoscopic ultrasound-guided fine-needle aspiration. Gut Liver 2016;10:51-57.

22. Bang JY, Varadarajulu S. Procore and flexible 19 gauge needle can replace trucut biopsy needle? Clin Endosc 2013;46:503-505.

23. Yasuda I, Iwashita T, Doi S. Tips for endoscopic ultrasound-guided fine needle aspiration of various pancreatic lesions. J Hepatobiliary Pancreat Sci 2014;21:E29-E33.

24. Kundu S, Conway J, Gilbert K, Geisinger K, Mishra G. Suction or no suction? Interval results from an ongoing prospective, partially blinded, randomized trial of endoscopic ultrasound (EUS) guided fine needle sampling of solid lesions. Gastrointest Endosc 2009;69:S248-S249.

25. Puri R, Vilmann P, Săftoiu A, et al. Randomized controlled trial of endoscopic ultrasound-guided fine-needle sampling with or without suction for better cytological diagnosis. Scand J Gastroenterol 2009;44:499-504.

26. Sahai AV, Paquin SC, Gariépy G. A prospective comparison of endoscopic ultrasound-guided fine needle aspiration results obtained in the same lesion, with and without the needle stylet. Endoscopy 2010;42:900-903.

27. Rastogi A, Wani S, Gupta N, et al. A prospective, single-blind, randomized, controlled trial of EUS-guided FNA with and without a stylet. Gastrointest Endosc 2011;74:58-64.

28. Iglesias-Garcia J, Dominguez-Munoz JE, Abdulkader I, et al. Influence of on-site cytopathology evaluation on the diagnostic accuracy of endoscopic ultrasound-guided fine needle aspiration (EUS-FNA) of solid pancreatic masses. Am J Gastroenterol 2011;106:1705-1710.

29. Kin T, Katanuma A, Yane K, et al. Diagnostic ability of EUS-FNA for pancreatic solid lesions with conventional 22-gauge needle using the slow pull technique: a prospective study. Scand J Gastroenterol 2015;50:900-907. 